\section{F. MELINI DE PAZ*}

Servicio de Cirugía Ortopédica

y 'Traumatología.

Hospital Universitario de Valme, Sevilla.

* Jefe del Servicio.

\section{Calidad y cualidad del titanio para su uso en cirugía ortopédica \\ Quality and properties of titanium used in orthopedic surgery}

\section{Resumen}

Puesto que en los momentos actuales se está usando el titanio de manera habitual como componente de todas las endoprótesis, y de manera cada vez más importante se está incluyendo en la fabricación de los implantes de osteosíntesis y estabilización osteoarticular, es necesario que los cirujanos ortopédicos nos acerquemos al conocimiento de sus bondades o de sus inconvenientes.

Iratamos por ello de situarlo en sus coordenadas de aplicación clínica, resaltando sus virtudes en los aspectos biomecánicos, en las garantías de biocompatibilidad que permiten que se pueda realizar por parte del hueso receptor el fenómeno de la osteointegración, y en general en la respuesta del huésped ante este metal no desde el punto de vista de la unión al mismo, sino de las reacciones adversas o no, que pueda ocasionar sistémica o localmente. Desde el punto de vista biomecánico, su ductilidad y resistencia y su gran capacidad de autorreparación por el mecanismo de la pasivación inmediata anulando por tanto el fenómeno corrosivo, son sus mejores credenciales. Biológicamente, su compatibilidad con el medio que lo recibe permitiendo el crecimiento hístico a su alrededor sin interferirlo, junto a su baja o nula capacidad de reacción a cuerpo extraño y mucho menos en la producción de fenómenos de sensibilidad son las otras características que avalan su uso. Como material endoprotésico, junto a indudables constataciones clínicas y de laboratorio que le situan como el mejor metal proosteointegración, otras tratan de encontrar sombras para su empleo.

Palabras clave: Metal. Titanio. Endoimplantes. Osteointegración.

\section{Summary}

Titanium is used commonly as a component of endoprostheses and it is being used with progressively greater frequency in the manufacture of osteosynthesis and osteoarticular stabilization implants. For this reason, orthopedic surgeons should be familiar with its advantages and disadvantages.

Titanium is discussed within the context of clinical applications, emphasizing its biomechanical virtues in ensuring the biocompatibility that makes osteointegration phenomena possible in the receptor bone and the general host response to this metal, less with respect to bone union than to the presence or absence of local or systemic adverse reactions. Biomechanically, titanium's ductility and resistance and its capacity for self-repair by immediate passivation mechanisms, which annul corrosive phenome$n a$, are its best credentials. Biologically, titanium's compatibility with the receptor medium favors tissue growth around it without interference, and its low or null capacity for inducing foreignbody reactions and sensibility phenomena are other features that contribute to its suitability for use. As an endoprosthetic material, indubitable clinical and laboratory findings show that it is the best pro-osteointegration metal, but other findings suggest drawbacks.

Key words: Metal. Titanium. Endoimplants. Osteointegration.

\section{Introducción}

El titanio es uno de los materiales de más reciente uso en los arsenales de la manufactura, puesto que en cantidades industriales sólo se comenzo a produ-

\section{Correspondencia:}

Dr. F. MELINI DE PAZ. Servicio de Cirugía Ortopédica y Traumatología. Hospital Universitario de Valme. Ctra. de Cádiz, s/n. Tel. y Fax: (95) 4596210.41914 Sevilla. cir a partir de 1948 y se introdujo en el campo de la cirugía como titanio puro a finales de los años 50. De él se conocía que era un metal muy blando y bien tolerado, aunque de aplicación limitada ${ }^{1,2}$. Ocupa el décimo puesto entre los elementos más comunes de la corteza terrestre, participándo con un $0,43 \%$ en su peso, y generalmente se presenta como componente minoritario de otros compuestos, muy repartido, bajo formas químicas muy diversas y generalmente en yacimientos muy pequeños, pero con una presen- 
cia frecuente en nuestro habitat, incluso en los alimentos.

El llamado titanio puro comercial (t.p.c) es un elemento químico único que contiene trazas de hierro, oxígeno, nitrógeno, carbono e hidrógeno. La cantidad de trazas de estos elementos influye en las propiedades mecánicas del titanio, permitiendo distinguirse hasta cuatro grados diferentes de t.p.c. El estándar internacional para el titanio como material de implante quirúrgico, existe desde 1978 (ISO 5832/2) y describe cuatro gradaciones según la composición química y las propiedades mecánicas, aunque en el de grado cuatro se distinguen dos variedades, según se haya trabajado el titanio en frío o bien se haya recocido. Las diferencias entre cada una de estas gradaciones estriban en las cantidades máximas de oxígeno, hierro o nitrógeno que posean (entre 0,03 y 0,05 para la cantidad de hidrógeno máximo; de 0,20 a 0,50 para la de hierro en que se vean participados y entre $0,18 \mathrm{y}$ 0,40 para la de oxígeno). Los intentos anteriores de crear implantes quirúrgicos a base de t.p.c. no tuvieron éxito porque la tecnología para producir t.p.c. de alta resistencia aún no se había desarrollado ${ }^{3}$. En la actualidad sin embargo, se han podido desarrollar implantes de titanio puro con mejores condiciones mecánicas y desarrollo tecnológico, hasta el extremo de que obviando los inconvenientes de las aleaciones, se emplea casi de forma sistemática el titanio puro en las artroprótesis de cadera para el componente acetabular, y como endoimplante rígido en algunas placas de osteosíntesis. La necesidad de aleaciones con aluminio, vanadio y niobio se reservan para los componentes femorales de las artroprótesis, si bien todo ello tiene una imagen cambiante en la industria casi año por año.

\section{Biomecánica y titanio}

Las características mediante las cuales el titanio se puede diferenciar de otros metales como material de endoimplante son la ductibilidad, la resistencia a la tracción, su módulo de Young, su capacidad de pasivación y autorrepasivación inmediatas, la posibilidad de recibir tratamientos de superficie que aún le convierten en más inerte, o su magnífico comportamiento tanto in vivo como in vitro detectado en las aplicaciones de laboratorio y clínicas que lo han empleado.

Comparados con materiales como el acero inoxidable, el titanio tiene una mayor ductibilidad, como se comprueba por su menor capacidad de deformación a la torsión, estando todos sus valores muy por encima de los valores mínimos requeridos por ISO 6475 para el acero inoxidable, lo cual le da una flexibilidad doble que la del acero, y además, en condiciones de deformación limitada, sus características de fatiga son buenas. Precisamente las aleaciones de alta resistencia consiguen con frecuencia esta alta resistencia a expensas de la ductibilidad ${ }^{4}$. Cuanto mayor sea la ductibilidad, más fácilmente se podrá moldear el implante para adaptarlo al contorno del hueso. Los materiales de implante cuya ductibilidad es baja no son aceptables para todo tipo de osteosíntesis, aunque sí puedan usarse en la cirugía articular protésica. Las aleaciones de titanio de nueva generación que combinan resistencia y ductibilidad, tales como las aleaciones de titanio beta, están poniéndose a punto en estos momentos para su uso clínico generalizado. Esta mayor ductibilidad es la que le confiere la mayor resistencia a la tracción ya que su punto de ruptura a la elongación es superior a la de otros materiales usados en los endoimplantes hasta su incorporación, al combinar a la resistencia mecánica la fexibilidad, factores éstos absolutamente imprescindibles, si queremos que un implante se comporte correctamente al ser aplicado a un hueso, permanecer en contacto con él y tener que soportar las solicitaciones mecánicas del mismo, sin interrumpir su potencial de modificación permanente, tanto en longitud en el individuo en crecimiento como en aposición en el adulto (Fig. 1). Esta baja rigidez del titanio en contacto con el hueso viene condicionada por tener un módulo de Young equivalente a la mitad aproximadamente del acero inoxidable, acercándose más a la del propio hueso, por tanto la deformación con que responde a una fuerza, aplicada a la misma tensión, es sensiblemente mayor. Pero además, las mínimas deformaciones repercuten en un momento de flexión también menor para el titanio, lo que supone un menor esfuerzo en el interior del mismo stress $^{5}$, lo cual oferta como consecuencia inmediata una mayor proclividad a la rotura por fatiga. Ello implica una mayor resistencia a la fatiga continuada, es decir, a la acción crónica sobre el implante, lo que en sí mismo ya constituye una diferencia fundamental contra el acero inoxidable, por ejemplo. En definitiva, si en igualdad de condiciones se actúa con cargas de-

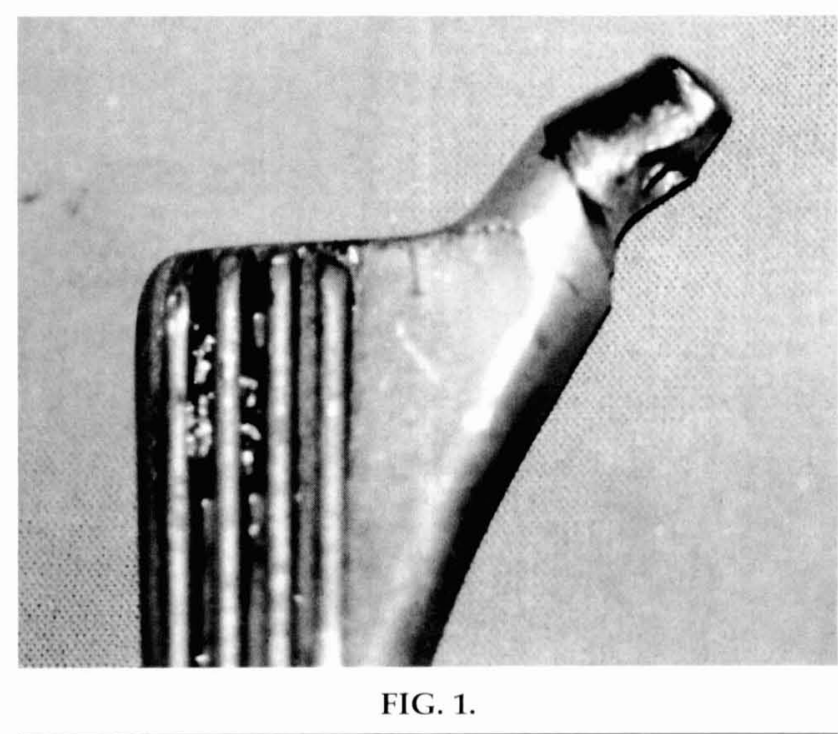


terminadas sobre el titanio y sobre el acero, el primero se deforma sin romperse en valores prácticamente dobles, al tener un módulo de elasticidad la mitad que el segundo. Respecto a la fricción, el titanio tiene un comportamiento dual que hay que conocer para evitar algunos de los errores que en cirugía endoprotésica y en un pasado muy reciene se llegaron a cometer. Tiene consigo mismo una nula capacidad tribológica ya que de su intercontacto y debido a su resistencia se producen detritus que aumentan el roce en la fricción al mismo tiempo que emiten partículas circulantes en el ambiente hístico periimplante puestas de manifiesto por una coloración pardo-negruzca-brillante en los tejidos circundantes y que sin embargo no responde a un mecanismo corrosivo, sino abrasivo (Fig. 2). Partículas que tampoco se ha visto que hayan provocado reacciones defensivas en el organismo. Por ello sólo se pueden usar en endoprótesis, como sistema modular con un material diferente como par de fricción, pero no consigo mismo. Sin

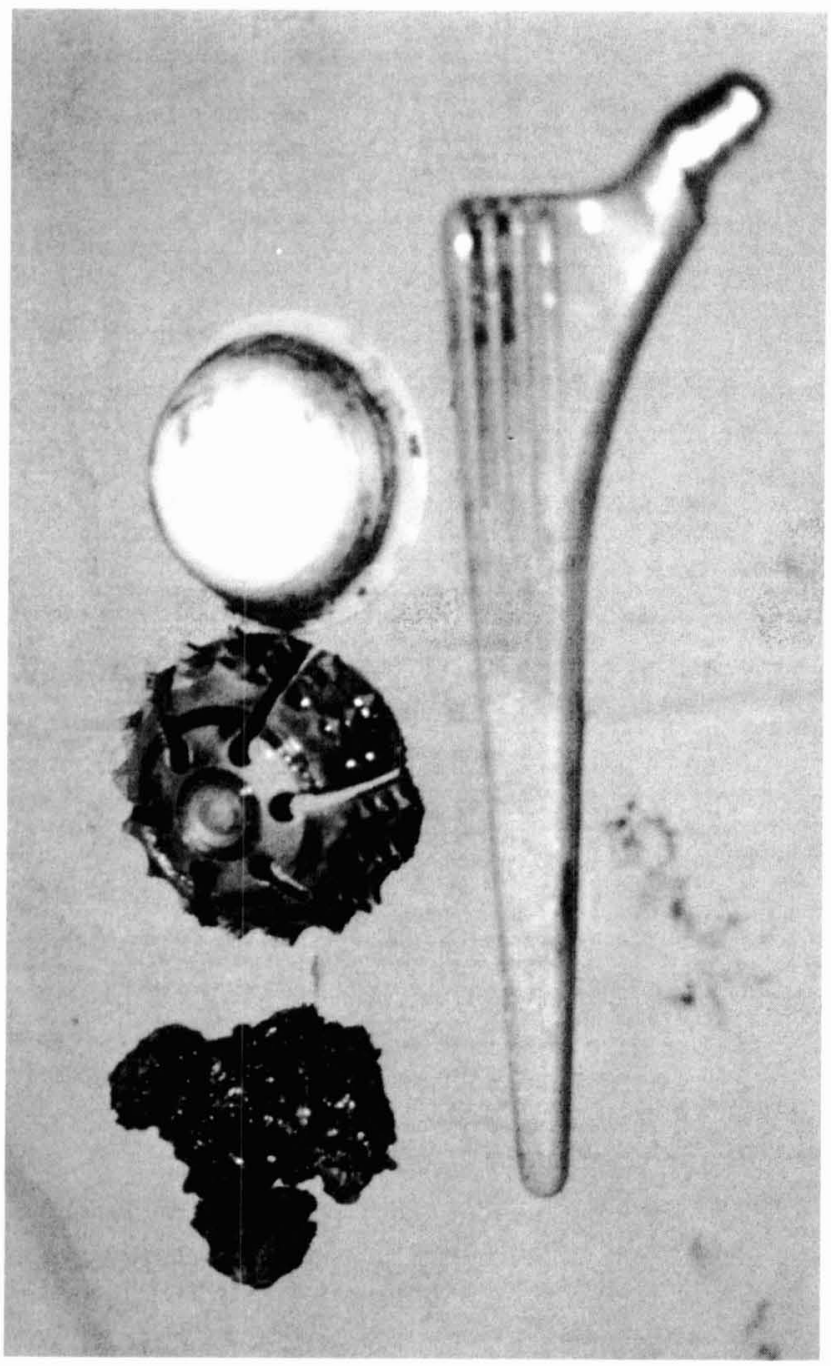

FIG. 2. embargo, hay metales que ya se han experimentado y se han tenido que rechazar, como el acero inoxidable o el cromo-cobalto, porque producían un par galvánico con el titanio propiciando el inicio del fenómeno de la corrosión electroquímica. Alguna artroprótesis de la rodilla hubo de ser retirada por ello. Sin duda, no obstante, parece que en estos momentos el material que mejores condiciones tribológicas había ofertado, fundamentalmente en los estudios in vitro, son las cerámicas tenaces, y dentro de ellas el circonio. Ello sin olvidar la eclosión de comunicaciones e intenciones que en este año está teniendo el par tribológico metal-metal en todos nuestros congresos. En cuanto a los endoimplantes no articulares, como en las placas y tornillos de osteosíntesis, también si se dejan con aflojamiento, no coaptación o movilidad secundaria en alguno de los componentes, se producen detritus grisáceos en los tejidos adyacentes sin ningún carácter nocivo puesto que las partículas in vitro se ha visto que son bien toleradas, y que, por otro lado, ha sido evitado este desgaste realizando en el titanio de implante determinados tratamientos mediante tapización con películas de superficie.

\section{Corrosión en el titanio}

Decimos que estos detritus no son productos corrosivos, porque la resistencia del titano a la corrosión es excepcional. Cualquier metal de los usados previamente tratan de hacerse resistentes a la corrosión al tapizarse con una capa de óxidos del propio metal de unos pocos átomos de grosor y a la que llamamos capa de pasivación al formarse óxidos de distinta estequiometría a través de una reacción exotérmica ${ }^{6}$. Todos los metales, cuando son puros, incluso el oro, son relativamente solubles en el agua, mientras que dejan de serlo al recubrirse de su capa de pasivación. El titanio se recubre de su capa de óxido de titanio mucho más rápidamente que el cromo, el cobalto o el acero inoxidable, y además de forma más estable y densa. Cuando esta capa es dañada en la acción quirúrgica, o posteriormente a su implante por los detritus óseos, metálicos o de cemento, se provoca una inmediata reacción del titanio, el cual toma oxígeno del propio medio para formar compuestos de óxido de titano, repasivándose y autorreparándose en segundos e impidiendo que se combine la acción lesiva del desgaste por abrasión con el desgaste por corrosión ${ }^{7}$ (Fig. 3). Ello explica que tenga un comportamiento similar al del platino frente a la corrosión. Respecto a la emisión de partículas y a la enfermedad del desgaste, hay varios trabajos, tanto en vivo como en laboratorio, sobre series de implantes protésicos, estudiando por ejemplo la membrana interfacial obtenida en algunas prótesis de revisión ${ }^{8}$ bajo microscopía electrónica, espectroscopia microquímica y análisis del tamaño de las partículas, comprobándose que la mayoría de 


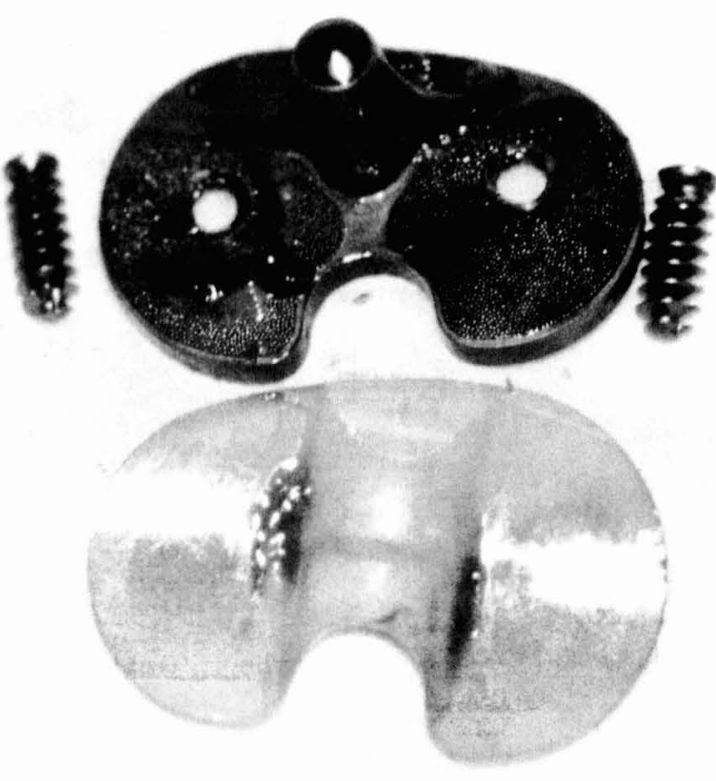

FIG. 3.

las partículas detectadas eran de polietileno y con un tamaño de 0,53 micrones $\pm 0,3$ y eran similares a las partículas que se ven en las bases de resinas que se usan en la manufactura de los cotilos. Se encuentran, por el contrario, muy pocas partículas de titanio, mientras que fragmentos de hueso, acero inoxidable y silicatos se pueden detectar en pequeñas cantidades. La mayoría de las partículas que se ven de polietileno son demasiado pequeñas para poderse apreciar con el microscopio de luz por lo que son necesarios o el electrónico o técnicas de espectroscopia (Fig. 4).

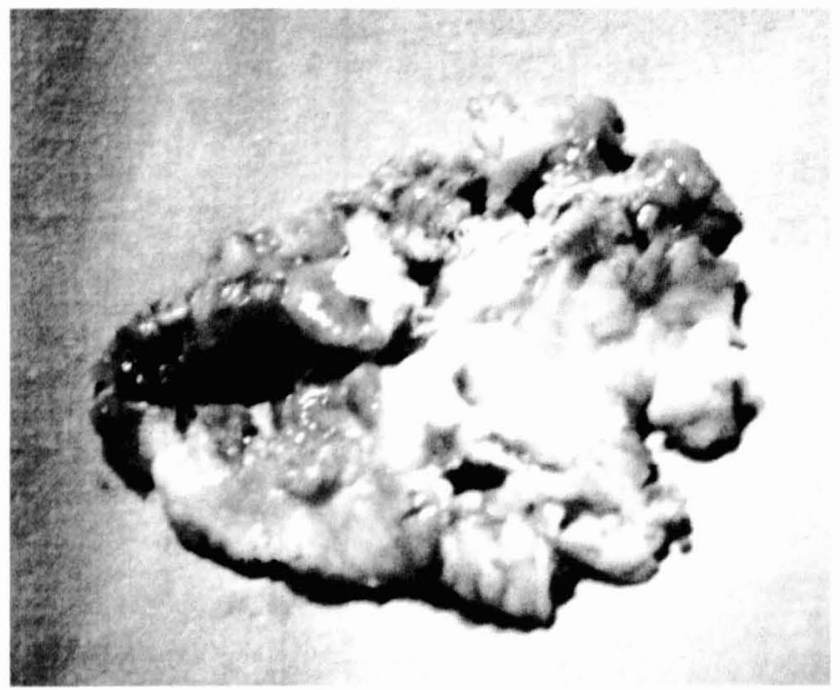

FIG. 4.

\section{Aptitudes tribológicas del titanio}

En el par tribológico de fricción para las prótesis de cadera, ha tenido un buen comportamiento la unión del titanio con el polietileno de ultraaltadensidad. Sin embargo, observamos paradójicamente que en algunas revisiones de la literatura se han notificado altos grados de reacción inflamatoria fagocitaria macrofágica que se inicia por una prótesis dolorosa sin ninguna sintomatología radiográfica ${ }^{9}$. Se publican también altos índices de desgaste con presencia de partículas ${ }^{10,11,12}$. Se admiten conclusiones sobre que si se usa el titanio o sus aleacciones ${ }^{13}$ hay que poner un especial cuidado en la presencia adyacente de cemento óseo puesto que aumenta exponencialmente la enfermedad del desgaste ${ }^{14}$. En seis casos revisados de uso de titano y sus aleacciones ${ }^{15,16}$ se describen amplios desgastes en la superficie articular de la cabeza que sólo se acusan en el vástago femoral cuando comienza el aflojamiento y no antes, o bien se describen amplias zonas de resorción ósea ${ }^{17}$ que producen aflojamientos protésicos y que están inducidas por los productos del desgaste de la cabeza femoral modular de Ti6A14V ${ }^{18}$. GALANTE hubo de admitir que el titanio y sus aleaciones no debían recomendarse como superficies de deslizamiento, como ya indicábamos en otro apartado de este trabajo ${ }^{19}$.

En publicaciones recientes, incluso a finales del pasado año ${ }^{20,21}$, se han mostrado los resultados obtenidos en un estudio en el cual se ha valorado el desgaste que se había producido en distintos tipos de prótesis usando cabezas metálicas de acero inoxidable, de cromo-cobalto y de aleación de titanio. El desgaste de polietileno observado fue de $0,6,0,5$ y $0,8 \mathrm{~mm}^{3} /$ año respectivamente. El análisis de varianza demostraba que la diferencia entre los 3 grupos no era estadísticamente significativa $(p>0,05)$. Los autores concluyen que el desgaste producido en el polietileno no es de resaltar en el comportamiento protésico y que los resultados del desgaste obtenidos con las cabezas recambiables de aleaciones de titanio no tenían una gradación estadísticamente significativa.

\section{Comportamiento biológico del titanio}

Respecto al tratamiento de su superficie en orden a aumentar su resistencia a la corrosión y la tolerancia tisular de los tejidos circundantes, se reviste a los materiales de titanio de una película superficial resistente a la abrasión y que se altera poco ante las manipulaciones que tienen lugar durante la aplicación del endoimplante o por las acciones posteriores de agresividad mecánica en su funcionamiento. Para ello se recubre el titanio de una capa superficial de nitruro reforzado que se produce sin manipulación química ${ }^{22}$. Sólo se logra por el efecto de la difracción de la luz sobre una película de óxido que ha de ser extremadamente fina. El aumento de grosor de la película puede 
producir cambios de color en la superficie del metal que no tienen ninguna significación física ni clínica.

En pruebas realizas in vitro ${ }^{23}$ se estudió el comportamiento de los tejidos cultivados en presencia de diferentes metales, comprobándose cómo no se observa ninguna inhibición en el crecimiento tisular en presencia del titanio, lo que si sucede con las sales de los otros metales, cuando se usaron cultivos orgánicos de fémur de pollo y de $\mathrm{rata}^{24}$. La biocompatibilidad en estos casos era buena para el titanio, aunque también lo era para metales como el $\mathrm{Ni}, \mathrm{Co}, \mathrm{Cu}$ y a mucho más bajas concentraciones para el V. En la misma línea experimental se trató de medir la corrosión determinando la cantidad de metal hidrolizado a través de las tasas de $\mathrm{pH}$ de los fluidos tisulares ${ }^{25}$ siendo los menos hidrolizados el Ti además de otros como el Zr, el Al v el Mo a un $\mathrm{pH}$ de 7.4. También se hicieron estas experiencias implantando barras metálicas de estos metales simulando condiciones de corrosión y se demostró su buena biocompatibilidad. De ello se pudo deducir que debido a la inhibición del crecimiento que se producía con los metales altamente disociables como el Ni, Co, $\mathrm{V}$, se hace aconsejable sustituir las aleaciones de Cro1619Ni11-14Mo2-4Fe e incluso las de Ti6A14V por el titano monofásico o por alguna de las aleaciones de Ti-beta que contienen las combinaciones Ti15Mo, Ti15Mo5Zr3Al, Ti12Mo6ZrSn, Ti6Al7Nb y Ti50Nb. El niobio $(\mathrm{Nb})$ precisamente es un metal que en principio parece que ofrece grandes capacidades futuras. Según las apreciaciones del laboratorio de investigación de Davos $^{26}$ los resultados obtenidos con aleaciones de metales que incluyen $\mathrm{ZrO}_{2}$ y $\mathrm{TiO}_{2}$ con una concentración hidrolizada de 10 elevado a menos $11 \mathrm{M}$ y de $3 \times$ 10 elevado a menos $6 \mathrm{M}$ en estado de saturación, confirman las excelentes características de tolerancia tisular al titanio que ya en la clínica se había advertido.

Por su parte in vivo se implantaron cilindros de titanio ${ }^{27}$ y de otros metales subcutáneamente a ratones determinándose el número de células redondas que se encontraran en la capa adyacente al cilindro como índice de la respuesta inflamatoria. De igual forma se contó el número de núcleos de células gigantes por milímetro cúbico, como índice de la reacción a cuerpo extraño, encontrándose en ambos casos una buena tolerancia al titanio ${ }^{28}$

De todo ello se puede entender cómo se comporta el titanio dentro del organismo en el caso de que se encuentre libre a través de los alimentos o de otra puerta de entrada, o bien cuando se encuentra formando parte de un endoimplante ${ }^{29}$. En el primer caso, el titanio es absorbido y eliminado en pequeñas cantidades por el propio tubo digestivo. Las cantidades que transitoriamente van quedando y manteniendo la tasa orgánica de titanio se encuentran en forma de soluciones saturadas debido a la baja solubilidad del mismo ya expresada, hasta una cantidad de 0,2 $\mathrm{mMol}$ que es la tasa de soporte del organismo. En el segundo caso, al encontrarse el organismo ya saturado con su tasa de titanio, el endoimplante no

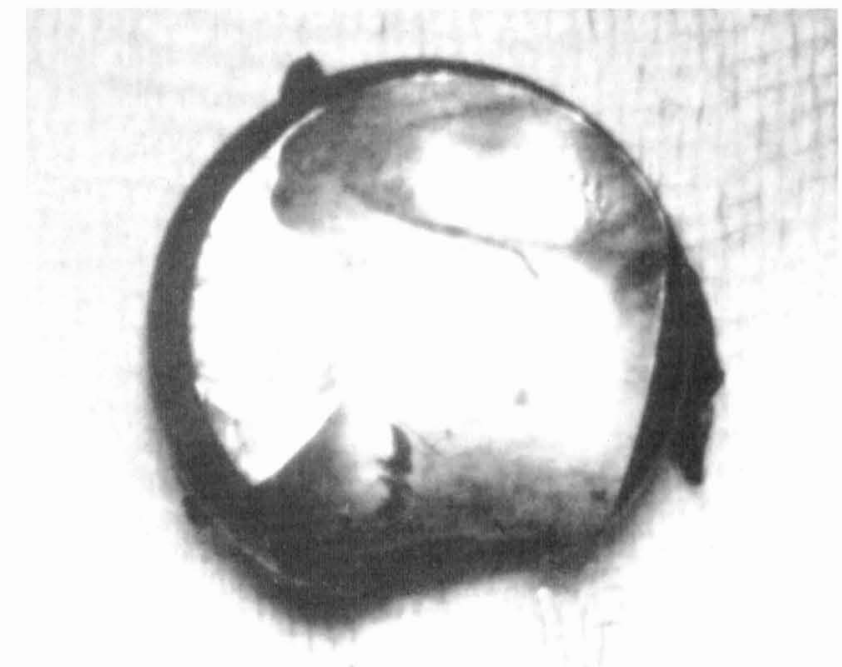

FIG. 5.

puede aumentar esta tasa libre, lo que sirve de protección ya que impide por ello la corrosión del implante o las reacciones alérgicas al mismo al no tener el organismo que rescatar el metal desde el implante para mantener su tasa orgánica. Por ello las partículas de desgaste del metal se han de comportar como inocuas. Lo que sí puede suceder, si estas partículas se acumulan en gran cantidad, son reacciones a cuerpo extraño con presencia de macrófagos o células gigantes, originando el fenómeno de la enfermedad de las partículas. De hecho, es muy reciente la aportación de que cuando se expone el titanio puro a un medio con presencia de macrófagos no se origina el fenómeno de la resorción ósea, ya que la respuesta celular obtenida es una disminución del factor de necrosis tisular por parte de los macrófagos, al mismo tiempo que un descenso de la prostaglandina E2 por parte de los osteoblastos, lo cual indica que no se produce una respuesta inflamatoria semejante a la producida por otras partículas: las de polietileno o de cemento óseo. Ello es lo que nos obliga a evitar un desgaste excesivo del titanio (Fig. 5). Pero en ausencia de fricción excesiva, es imposible que se presenten reacciones locales debido a la bioactividad de la superficie del titanio, porque éste cuando está oxidado, hidroxilado y recubierto de su capa de productos de absorción tisular, no puede ser reconocido por el organismo como un cuerpo extraño.

\section{Osteointegración y titanio}

Los implantes de titanio necesitan por ello ser estables de forma primaria para evitar el desgaste pudiéndose lograr entonces su integración fija y duradera al hueso, como se demuestra por el crecimiento del hueso sobre la superficie del titanio sin interposición de ningún tipo de capa conjuntiva en los implantes fe- 


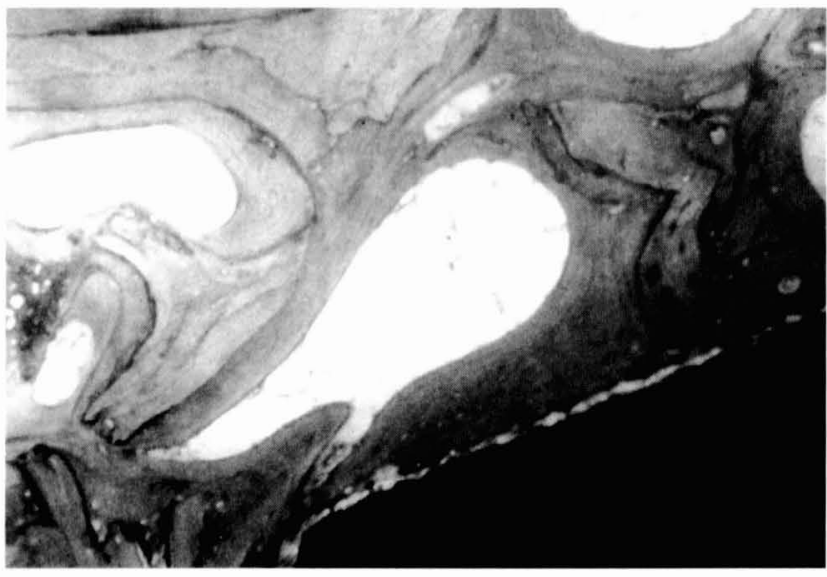

FIG. 6.

morales de las artroprótesis, lográndose unas adherencias entrambos que llega a sobrepasar la resistencia del propio hueso. Esto es fácil de comprobar cuando en autopsias o en reintervenciones se tiene que extraer un vástago femoral de titano y sólo se logra con fragmentos de hueso esponjoso adheridos a su superficie. Pero para ello, la superficie de titanio ha de estar revestida de microestructuras que permitan el crecimiento del tejido osteoblástico (Fig. 6). Este crecimiento óseo está comprobado que no ofrece diferencias cuando se hace sobre la superficie del titano puro o sobre la de aleaciones del titanio, mientras que sí está en relación con la cantidad de superficie que se haya tratado para darle porosidad o incluso con el volumen que tengan estos poros. En los implantes realizados por diversas vías para la cirugía raquídea, evita las segundas intervenciones por retirada del material implantado cuando ya había completado su función estabilizadora primaria. Esta ventaja es también claramente indiscutible en su uso por la cirugía maxilofacial y conlleva otro tipo de discusión para la traumatología de los miembros.

\section{Biorreacciones adversas y titanio}

Contradictorios estudios para comprobar la sensibilidad que el huésped tenía ante el titanio se han hecho sobre las membranas procedentes de exéresis de prótesis fracasadas en cinco pacientes a los que se le había implantado prótesis compuestas por revestimiento interno de polietileno, cotilo metálico de aleación de cromo y fijación de ésta última mediante tornillos de aleación de titanio ${ }^{30}$ utilizando anticuerpos monoclonales antihumanos de ratón para macrófagos, linfocitos $\mathrm{T}$ y $\mathrm{B}$, neutrófilos y células gigantes. Los autores creen que existe sensibilidad al titanio en las membranas estudiadas y admiten estar en controversia con otras publicaciones aunque recuerdan que datos de sensibilidad ya fueron descritos por PETERS y cols. en 1984 usando para ello un paciente con un marcapasos de titanio y realizando las pruebas mediante cutirreacción.

Lo cierto es que siempre se ha especulado sobre la respuesta autoinmune del huésped y hasta ahora sólo se ha encontrado, tras los implantes de titanio en animales de experimentación, la presencia de linfocitos $\mathrm{T}$ y no de $\mathrm{B}$ ni de células plasmáticas en los alrededores protésicos, siendo las cutirreacciones con titanio en dichos animales siempre negativas, por lo que la duda ante estas reacciones autoinmunes debe persistir ${ }^{31,32}$.

Sin embargo, lo que a nosotros nos parece un hallazgo importante y estimulante para el uso del titanio como material endoprotésico, con menor capacidad que otros para intervenir en los fenómenos del aflojamiento aséptico, es la comprobación de que cuando se coloca el titanio puro en un medio que contiene macrófagos, se produce una disminución en la secreción del factor de necrosis tisular por parte de los macrófagos y de la prostaglandina E2 por parte de los osteoblastos, al mismo tiempo que no es estimulada la presencia de la Interleukina 1, siendo éstos como son los grandes responsables de la reabsorción ósea desde la membrana de intercara prótesis-hueso ${ }^{33}$.

\section{Bibliografía}

1. Williams DF. Biocompatibility of implant materials. Sector Publishing Ltd. London, 1976.

2. Williams DF. A model for biocompatibility and its evaluation J Biomed Eng. 1989;11:185-91.

3. Pohler O, Steinemann S, Perren SM. Material propuesto para implantes: titanio puro. Injury. 1991; vol 22,supl. 1.

4. Doobs SS, Scales IT. Behavior of comercially pure titanium and T-318 (Ti6-A14-V) in orthopedic implants. In Luckey HA, Kubli F (Jr): titanium alloy in surgical implants, ASTM STP 796. Philadelphia, ASTM, 1983:173.

5. Perren SM. Fuerza, tensión, deformación bajo carga, resistencia. En Manual de osteosíntesis. Técnicas recomendadas por el grupo de la AO. Edit Springer-Verlag Ibérica. 1993:16.

6. Palacios Carvajal J, Hernández-Ros C, Olaguibel J, Rohde Thielen M, Fernández Fairen M. Bases biomecánicas y metalúrgicas de los implantes utilizadas en cirugía ortopédica y traumatología. Ponencia Oficial XII Congreso Hispano-Luso Traumat. Y Ortop, Oporto, 1979

7. Melini de Paz F. Las endoprótesis en la rodilla. Rev $S$ and Traum Y Ort. 1995;15(1):3-16

8. Shanbhag AS, Jacobs JJ, Glant TT, Gilbert JI, Black J, Galante JO. Composition and morphology of wear debris in failed uncemented total hip replacement. J Bone Surg Br. Jan 1994;76(1): 60-7.

9. Black J, Sherk H, Bonini J, Rostoker WR, Schajowicz F, Galante J. Metallosis associated with a stable titanium-alloy femoral component in total hip replacement. J Bone Joint Surg. 1990;72: 126-130.

10. McKellop H, Hosseinian A, Borgoyne K, Clarke Y. Polyethylene wear against titanium alloy compared to stainless steel and cobalt-chromium alloys. In proceedings of the Second World Congress on Biomaterials, Tenth Annual Meeting of the Society for Biomaterials, Washington DC. 1984:313.

11. McKellop H, Rostlund TV. The wear behavior of lon-implanted Ti-6A1-4V against UHMW polyethylene. Unpublished data. Materials evaluated on a multichannel screening device. J Biomed Mater Res. 1981;15:619-53.

12. Rostoker W, Galante JO. The influence of titanium surface treatments on the wear of medical grade polyethylene. Biomaterials. 1981;2:221-4. 
